\title{
SHENGTAI LUYOU: CROSS-CULTURAL COMPARISON IN ECOTOURISM
}

\author{
Ralf Buckley \\ Carl Cater \\ Griffith University, Australia
}

\section{Zhong Linsheng}

Tian Chen

Institute for Geographical Sciences and Natural Resources Research Academy of Sciences, China

\begin{abstract}
We compare the Sinophone term shengtai lüyou and the Anglophone term ecotourism through reciprocal translations of relevant literature and grounded iterative comparisons of conceptual components and practices. The Chinese concept of shengtai lüyou is similar to the Western concept of ecotourism but with key differences: a role in promoting human health; a predilection for human art and artefacts to enhance nature; and no limitations on scale. These differences are reflected both in academic literature and in practical implementation by government agencies and the tourism industry. Shengtai lüyou is thus a cultural analogue of ecotourism, not simply a translation. There are three steps in its evolution. Traditional Chinese culture, different from the West, provided the context. Recent concerns over environmental impacts, management, education and community equity in tourism, parallel to the West, provided favourable circumstances. The Western term ecotourism, introduced into Sinophone literature by Chinese researchers in the mid 1990s, provided a catalyst. Just as China has learnt from ecotourism, the West can learn from shengtai lüyou.
\end{abstract}

Keywords: China; West; health; nature; park; tradition; definition

\section{INTRODUCTION}


Tourism which relies on the appreciation of nature as a primary attraction currently comprises a very significant subsector of the tourism industry worldwide. It has considerable consequences for many regional and national economies, local communities, and the natural environment. Some of these effects are positive and others negative, and a wide variety of government policy and regulatory instruments, educational approaches, and local-scale corporate and environmental management tools are used in attempts to adjust the relationship between these factors. Both the practices and principles involved in this field have been described, promoted and analysed extensively in the Anglophone literature, under the broad heading of ecotourism (Fennell 1999; Weaver 2001; Weaver and Lawton 2007).

Precisely the same practical considerations and theoretical concerns regarding the various interactions between tourism and environment also apply with equal force in continents and cultures with different languages (Buckley 2003; Mader, 2003; Cater 2006; Braden and Prudnikova 2008). A global perspective on ecotourism, therefore, requires a review of literature in multiple languages. This applies whether the issue of concern is, for example: global trade in tourism services; the use of tourism for local poverty alleviation; the social consequences of cultural interactions; the management of tourism and recreation in protected areas; or any other aspect of the sector. Here we focus on China.

China is the world's most populous country, with a particularly long and continuous written history, and a cultural tradition of nature appreciation dating back several millennia. During recent decades, academic institutions and government agencies throughout China have had access to English-language literature across a broad range of fields and disciplines, through an active and widespread translation program. Their counterparts in the West, in contrast, have no access to Chinese-language literature unless they themselves are individually fluent in written Chinese. A number of English-language ecotourism books (eg Buckley 2003) have been translated in full and republished in China; but Chinese-language ecotourism texts (Yang, Zhong and Ming 2000; Zhong, Zhao and Xiang 2003; Lu and Wang 2004; Zhong, Yuan and Luo 2006) have not been translated into English. English-language ideas and information on ecotourism and related topics, therefore, are available within China at least to specialists who search for them. In addition, there is a much larger self-referencing 
Chinese-language academic and government literature covering the same topics from a purely Chinese perspective.

\section{Methods}

Our focus in this contribution is on the conceptual distinctions between corresponding terms in China and the West, the ways in which those distinctions reflect different cultural histories, and their international implications in both theory and practice. Our core approach was an iterative comparison of Sinophone and Anglophone literature and practice, carried out during a one-year visit to Australia by ZLS. Since ZLS speaks English but RB and CC do not speak Chinese, these discussions, and the results as presented here, were carried out in English. We acknowledge that this may in itself influence our perceptions of the issues under study. Our initial aim was to review the Chinese-language ecotourism literature so as to make it accessible to English-language researchers. During this process, however, it became apparent that shengtai lüyou, the Chinese term used to translate the English term ecotourism, might represent a rather different concept. Accordingly, our primary aim here is to compare the conceptual bases and practical expressions of these two terms. If evidence indicates that there are no significant differences between the terms, then Chineselanguage information on shengtai lüyou in China can be aggregated, or compared directly, with English-language information on ecotourism in the West. If the two terms do in fact refer to significantly different concepts and practices, then comparisons between continents become more difficult, but arguably more interesting.

Our analytical approach was as follows. We reviewed the Anglophone academic literature on ecotourism, and the Sinophone academic literature on shengtai lüyou, independently, so as to identify: the components considered in various definitions of each, the importance attached to each component, and the degree to which each may be agreed or contested. There is an extensive literature to be consulted in each language, albeit with a number of recent review articles. These initial reviews were carried out in the original languages of the articles concerned, by RB and ZLS respectively, with no reciprocal translation. From these, we compiled a joint list of attributes and criteria, in English, for the two terms simultaneously. We paid 
particular attention to components which may differ between the two concepts; and to elucidate these further, ZLS translated key sections of relevant Chinese-language publications into English. For each of these criteria, we then compiled Chineselanguage data on both the principles and practices of shengtai lüyou, in order to test for any significant differences from ecotourism. Again, relevant extracts from Chinese-language publications were translated by ZLS, so that final comparisons and analyses could be carried out jointly in English.

To provide grounding for these comparisons, information on relevant practices in Chinese outdoor tourism and protected area management was also available from a series of field visits to various parts of China by each of the authors, separately, over several decades. In particular, over the quarter-century period from 1983 to 2007 inclusive, RB visited most of the country's major ecosystems except those of Heilongjiang in the far north-east. Finally, to provide triangulation, CC made a threemonth visit to ZLS, TC and other ecotourism researchers in China during late 2007, to discuss and refine the draft results. The results presented below are thus derived from an iterative process of discussion, data collection and debate over a two-year period.

There is one additional methodological issue which requires clarification, namely the definition or delineation of the two cultures compared here. The terms Western and Chinese may have multiple meanings, depending on who is using them and in what context. Here, we have adopted a broad ethnopolitical perspective: China as seen from the West, and the West as seen from China. We use the term Chinese to refer principally to the geographic area of the modern People's Republic of China; the dominant traditions of Chinese cultural philosophy as currently reflected amongst the Han people; and the documentary record in the Chinese written language. We recognise that there are many different ethnic groups, minority peoples and spoken languages within China, and that different groups share these traditions to different degrees. We also recognise that there are many people of Chinese ethnic origin, including many university researchers, living in Western nations, so that interactions between Western and Chinese thought and practice occur amongst these communities as well as within China itself. These, however, are second-order issues for our current analysis. By the term Western, we refer essentially to the peoples of western Europe and their colonial or imperial offshoots: that is, the modern-day nations of western 
Europe itself, North and Latin America, and Australia, New Zealand and South Africa. Again, we recognise that these modern states also include Indigenous and First Nations peoples, and also that people of European descent form neither a majority nor the political leadership of southern African nations. Regarding the study of ecotourism specifically, however, these nations are linked by a largely common academic heritage, expressed principally in English but also in other European languages. The key issue, from a Chinese perspective, is that the West is not limited to Anglophone nations or academic literature.

In order to carry out a higher-level conceptual and cultural comparison between shengtai luyou and ecotourism, we must first condense a considerable volume of published information. We analyse and present this here following a structure which reflects its sources and stakeholders, since, as in the West, different Chinese stakeholders may have somewhat different interests and ascribe somewhat different meanings to the same terms. Since this is an Anglophone publication whose Western academic readers are familiar with, and have ready access to, relevant Anglophone academic literature and Western practices, we give more emphasis here to the Sinophone literature and Chinese practices. Chinese-language literature is cited here in translation, and the precise titles of these citations are not definitive; in many cases, similar phrases or terms could be used to convey the same Chinese concepts.

The term shengtai lüyou first appeared in the Chinese-language academic literature in the early 1990s (Wang 1993). Shēng tài is translated as ecology, lü yóu as tourism, so the direct translation is ecological tourism. Our analysis here seems to be the first occasion in which this phrase has been used in the English-language academic literature. Previous English-language publications on this topic, notably in regard to tourism in protected areas in China, have simply used the term ecotourism without drawing the critical distinctions which we examine here.

Just as shengtai lüyou and ecotourism may have somewhat different meanings, the same applies to many of the words used to analyse the concepts involved in each. Many of the Chinese words, phrases and concepts translated to English by ZLS for the purposes of this analysis could be represented by a number of different alternative English words, depending on the precise context. This is a common issue in any form 
of translation. Rarely, especially for languages with very different historical roots, is there a one-to-one correspondence between words. There are many concepts for which there are multiple English synonyms, and there are many families of English words expressing closely related concepts. Equally, however, there are many single words in English which correspond to an entire family of related words in other languages: the many different Arabic words for different degrees of thirst, for example, or Inuit words for different types of snow.

Since none of the authors of this contribution are linguists or translators by profession, we have necessarily relied on dictionaries and discussions to elucidate the precise intentions of different terms. We acknowledge that this introduces a further element of uncertainty into our analysis. In particular, there were many initial translations by the Chinese authors which were difficult for the Anglophone authors to comprehend. In these cases, we searched for alternative translations in Chinese-English dictionaries, and then discussed which was most accurate, in an iterative manner. For example, does the word "consanguinity" mean the same as the more common word "relationship", or do we need the more precise though archaic term? Should a particular Chinese phrase be interpreted as "learning about nature" or "understanding nature”? Is an "ecological perspective” the same as "ecology theory”? Does "guidance" refer to natural history interpretation by a human guide, or internal guidance by an individual tourist's understanding of ecology? Such questions arose for almost every sentence of almost every Sinophone publication considered for this comparison.

\section{CRITICAL COMPARISONS OF SHENGTAI LÜYOU AND ECOTOURISM}

\section{Universities}

University contributions may be considered in two categories, namely research and teaching. Within the Anglophone research literature, the first mention of ecotourism in China seems to be that by Liu and Dowling (1991). The first discussion on possible cultural differences between Western and Chinese applications of the ecotourism concept seems to be that of Sofield and Li (1998). Li (2006) later pointed out that Western practices of community development in ecotourism do not necessarily apply 
in China. A review by Wen and Tisdell (2001) gave a broad overview in a development economics context. The majority of publications, however, have focussed on particular study areas (eg Stone and Wall 2003) or on tourism in protected areas (Zhao 1999; Li and Han 2000; Han and Zhuge 2001; Li 2002; Lindberg, Tisdell and Xue 2003; Sofield and Li 2003). More recently Zhong and Buckley (2007) identified a number of reasons, essentially cultural, why western tourism ecocertification schemes have achieved such low acceptance within China; and Huang, Deng and Zhong (2008) examined the role of forest parks, as distinct from national parks. Overall, the English-language literature on ecotourism and related topics in China is sparse.

There is an extensive Sinophone academic literature employing the term shengtai lüyou, comparable in scale to the entire English-language literature on ecotourism. Searches (by ZLS) on the Chinese-language version of Google Scholar ${ }^{\circledR}$ at the end of 2007 located over 1600 publications using the key phrase "shengtai lüyou”, though many of these are derivative and highly localised. Recent Chinese review articles, cited in Table 1, have identified over 100 publications which included definitions of shengtai lüyou. As in the English-language literature on ecotourism, different authors commonly use slightly different phraseologies. Direct transliterations to English retain similar minor differences, reflecting the difficulties raised earlier. Comparisons at the conceptual rather than linguistic level are thus more robust, and this is the approach adopted here. Key references include, e.g.: Wang (1995), Guo (1997), Chen and Liu (1998), Wang (1998), Niu (1999), Zhang and Hai (2000), Chen, Wang, and Liu (2001), Cheng and Zhang (2001), Jin, Wang and Cai (2001), and Wu and Wu (2001) on early development; Han and Zhuge (2001), Li and Han (2000) and Li et al (2008) on protected areas; Liu and Bao (1996) on environmental impacts; Liu, Chen and Tang (2006) and Zhang (2007) on standardisation; and Wang et al (2001), Xiao and Xiao (2005), Li, Gao, Wei and Yu (2005), and Xu (2006) on recent frameworks.

The three final columns in Table 1 summarise Western conceptions of ecotourism at a similar level of detail, derived from recent reviews and analyses such as Weaver and Lawton (2007) and Buckley (2008). The first column includes only those components which are common to all definitions and agreed by all stakeholders. The second column also includes criteria which have been proposed by some analysts and 
accepted by some stakeholders, but not necessarily by all. The final column identifies criteria or concepts which are included by at least some Chinese authors in definitions of shengtai lüyou, but not by their Western counterparts in definitions of ecotourism.

One key issue, in examining this table, is that most of the Chinese authors did not set out to analyse the Chinese concept of shengtai lüyou. Rather, they were simply aiming to introduce the Western concept of ecotourism to a Chinese readership, and used the phrase shengtai lüyou solely as a translation. It is therefore not surprising that only a few of these authors specifically identify the key distinguishing factors between ecotourism and shengtai lüyou. Authors such as Liu (1998), Niu (1999), Yang, Ouyang and He (2005), Ye and Xue (2005), Deng and Wu (2006), Li and Chen (2006), Xu (2006), Kong and Wang (2006) and Yuan, Wu, Chang and Wu (2007), for example, view shengtai lüyou through a Chinese cultural lens. These publications thus represent a blending of Western and Chinese thought, expressed in Chinese; they do not attempt to discriminate between Western and Chinese perspectives. It is not until Western and Chinese perspectives are applied simultaneously, as here, that cultural differences become noticeable. Thus the critical question, from the perspective of this analysis, is not how Chinese researchers translate the English term ecotourism into the Chinese term shengtai lüyou, but how the concept of shengtai lüyou has been understood and implemented in practice within China.

University contributions to shengtai luyou and ecotourism include teaching as well as research. Western academic institutions have offered courses in subjects such as leisure studies and recreation, with components on protected area management, for many decades. The first full three-year undergraduate degree in ecotourism began taking students in 1993, and a number of Western universities now offer majors or, less commonly, degrees in ecotourism. Different universities focus on different aspects, depending principally on the academic discipline within which the degree is based.

In China, university training in shengtai lüyou started within the academic discipline of forestry, and indeed within a specialised forestry university, the Central-South Forestry University (CSFU) in Hunan Province. In 1987, CSFU recruited its first group of postgraduate students in forest shengtai lüyou. In 1993 the same university 
began offering a major in this field, and four further forestry universities later followed suit (Yang et al 2000). In 2001, one of these opened an entire university department in shengtai lüyou.

Since the turn of the millennium, Chinese universities have had access to Chineselanguage teaching texts in shengtai lüyou (Yang et al 2000; Zhong et al 2003; Lu and Wang 2004; Zhong et al 2006); and elective courses in this subject are now offered by a number of well-known universities which are not specialised in forestry. This parallels the growth in Chinese university teaching in tourism more generally (Xiao 2000). Across the Chinese university sector as a whole, however, there is still a strong emphasis on the specialist forestry universities and the forestry context. In Western universities, in contrast, ecotourism teaching is housed largely within disciplines and departments of tourism and business, or occasionally geography and environment. Those where tourism teaching is housed within a forestry faculty, such as University of Montana, are the exception. The forestry context thus differentiates Chinese university courses in shengtai lüyou quite significantly from Western university courses in ecotourism.

\section{Government and NGOs}

A number of Chinese national and provincial government agencies, and national and international non-government organisations, have taken steps to promote the principles and practices of shengtai lüyou. A chronology of significant events is outlined in Table 2. Initially, the government promoted the definition of ecotourism put forward by The International Ecotourism Society (1990). More recently, a draft national standard (Zhong 2006) incorporated its own definition of shengtai lüyou. As for ecotourism in the West, there is little or no Chinese legislation designed specifically to regulate shengtai lüyou, but there are numerous laws and regulations which affect its various components. As in the West, various different government agencies and Ministries are responsible for different areas of legislation: for example, those relating to building and construction, water resources, pollution control, forest management, protected areas, and the operations of private commercial businesses. The agency responsible for tourism sees its role principally as promotion rather than regulation; this also corresponds to practices in the West. 
As with ecotourism in the West (Weaver 2001; Buckley, 2004), the development of shengtai lüyou is greatly influenced by land tenure. Many of the icon sites for shengtai lüyou are inside protected areas (Zhang, Xu and Huang 2005), but there has also been significant interest from government agencies responsible for forest management and for urban public lands. The earliest written records of protected areas in China are from the Ming dynasty (1368-1644 AD) when Emperor Zhu Li ordered the protection of forests around temples and monasteries. The modern system of protected areas dates from the 1950s (Liu, Kong and Chen 1997). China currently has an extensive system of protected areas at all levels, from internationallyrecognised World Heritage Sites and Biosphere Reserves, to national and provincial parks of various types, and public reserves run by local municipalities. There is a similar hierarchy of protected areas in most Western nations. Currently, China has over 5000 protected areas of various types, with management responsibilities shared between a number of different agencies. Shengtai lüyou is legally permitted, and indeed promoted, within all of these categories, though it may be restricted by zoning provisions in particular areas. Under the Chinese protected area system, reserves nominally consist of a core area allocated solely to conservation, surrounded by a buffer zone where recreation, tourism and other activities are permitted.

As in a number of Western nations, notably the USA, the national forestry agency in China has for many decades promoted the use of its lands for recreation as well as logging (Shen 1995; Tan, Gu and Chen 2007). By 2005 there were over 500 National Forest Parks and a further 1200 provincial forest parks (Huang et al 2008). Entry fees are charged, and in 2005 these totalled RMB 8.4 billion, a little over US\$1 billion, from 174 million visitors (CSFA 2006). This figure compares with a mean per capita GDP of US\$1000 in 2003, so it represents a substantial sum. The approach taken, and in particular the terminology used, shifted significantly between the 1980s and the 1990s. In the eighties, the principal Chinese term used corresponded most closely to the English word recreation. By the nineties, however, the key term used was shengtai lüyou. Forest parks in China were established primarily for recreation, rather than conservation, and are managed with aesthetic rather than ecological precepts in mind (Huang et al 2008). 
Chinese domestic visitation to protected areas and forest parks increased sharply in the early 1980s, as legal and political restrictions on domestic travel and economic activity began to ease. At that time there was rather little general public awareness of environmental protection issues within China, or indeed arguably within many Western nations, and visitors made little attempt to limit their impacts. In addition, forest parks were established principally as places for recreation (Huang et al 2008), where people may quite legitimately go simply to eat, drink, play games and sing songs. It is possible that the cultural perception of parks as playgrounds may have been extended to include national parks established for conservation. There are also cultural differences in the preferred recreational uses of national parks within the West. Within the US national park system, visitors of Hispanic ethnic origin reportedly prefer different activities to those of northern European descent, even though in Latin American national parks, gringos and Latinos may like similar activities. In South African national parks, people of Indian ethnic origin apparently prefer different activities to those of European origin, even though there may be no such distinction for visitors to national parks in India itself. The difference between China and the West, in regard to visitor perceptions and uses of protected areas, is hence one of degree: majority preferences differ, even though minority preferences may overlap.

The combination of increasing visitor numbers, activities and behavior in Chinese protected areas in the 1980s created significant environmental impacts. In addition to high visitor impacts, there was also extensive construction and development. In Wulingyuan World Heritage area this reached such a scale that it raised international concern over deterioration of World Heritage values (Kuang 2004). Surveys by Han and Zhuge (2001) found that litter, noise and water pollution from intensive visitor use were reported from $44 \%, 11 \%$ and $12 \%$ of nature reserves respectively. Yang, Wen and Wang (2002) found significant microbiological impacts on water quality in a nature reserve in Yunnan Province, as a result of heavy tourist use. It was at least partly in response to issues and impacts such as these that Chinese researchers began to examine and promote the Western concept of ecotourism. Similar impacts and concerns have occurred in the West. 
Even though China has adopted the same international classification system for protected areas as used by Western nations (IUCN 1994), there are still significant cultural differences between the practicalities of parks in China and the West. In particular, it is commonplace for high-ranked protected areas in China to include a wide variety of built structures which are themselves considered as part of the attraction and experience, not merely as infrastructure to allow visitors to enjoy the natural environment. Examples include temples, pagodas, scenic bridges and arches, sculptures, inscribed and painted calligraphy, and so on. To the degree that management and presentation of protected areas for conservation and recreation reflects or forms part of shengtai lüyou, therefore, these differences do support the view that there is indeed a cultural distinction between shengtai lüyou and ecotourism.

\section{Industry}

As in the West, China has a commercial tourism industry which provides paying clients with guided nature-based experiences, either contemplative or adventurous, and this has grown rapidly in recent years. As in the West, the proportion of that commercial industry which follows the various principles propounded for shengtai lüyou is difficult to quantify (Zhang 2002). As for ecotourism in the West, shengtai lüyou is not solely a commercial product sector. Descriptions and classifications of shengtai lüyou products in China (Chen 1996; Chen and Zhang 2001; Zhong et al 2003; Zhang and Li 2004; Zhong, Liu and Tong 2007) include a wide variety of activities which would generally be classed, in the English-language literature, as adventure or cultural rather than nature or ecotourism. Advertised tours include: terrestrial adventure activities such as trekking, horseriding, climbing and skiing; water-based adventure activities such as rafting, fishing, diving, sailing and surfing; nature-based activities such as birdwatching, photography and snow viewing; and cultural activities such as traditional wrestling, archery and fishing, collecting mushrooms and other wild foods, and visiting archaeological sites. Thus it seems that aggregate product concepts put forward in the West (Fennell 1999; Buckley 2000) are equally valid in China.

During the last few years, domestic outlets for the clothing and equipment used in outdoor recreation and adventure tourism have proliferated throughout China. The 
authors' personal experiences of nature and adventure travel in China over the past quarter century, including the associated commercial industry, provide historical verification that the expansion in this sector is a recent phenomenon. Additional confirmation is provided through Chinese-language articles written by Chinese adventure travellers themselves, in industry publications such as the Chinese edition of Outside magazine.

In China as in the West, a number of different legal structures are available for private business enterprises. Whilst there are some very large enterprises owned by single individuals, a more commonplace structure for larger-scale businesses is the jointstock corporation, where shares are individually tradeable through stockmarket transactions. The Chinese stock market first commenced operations in the early 1990s, and at the turn of the millennium there were about 30 joint-stock tourism corporations in China. Many of these had commercial interests associated with icon ecotourism destinations such as Mt Tai, Mt Emei, Mt Huong and Zhaongjiajie (Dai and Shu 2000).

\section{Tourists}

Limited information is available on the numbers, demographics, socioeconomic characteristics and preferences of Chinese domestic tourists, Chinese outbound tourists and international tourists inbound to China. By far the majority of tourism within China is domestic, with around 1.4 billion domestic tourist trips in 2006 as compared to around 22 million international arrivals (China National Tourism Administration 2007). There is apparently as yet no national study of shengtai lüyou amongst Chinese tourists, but there have been a number of small-scale surveys (Yang et al 2000; Zhong and Yang 2005; Zhong et al 2007).

A survey of visitors to Dinghushan Nature Reserve in Guangdong Province carried out by Lindberg and colleagues in the early 1990s (Xu and Kruse 2003), found that close to half (46\%) of visitors listed appreciating nature as the most important motivation. Visitors also gave high scores to understanding nature (38\%) and preserving tranquillity (45\%). Similar results have been reported more recently for visitors to the Wuyishan World Heritage Area in Fujian Province, where $\mathrm{Wu}$ and $\mathrm{Hu}$ 
(2004) found that the primary motivation for two thirds of visitors was to experience, enjoy and understand nature. At Taibai Mountain National Forest Park in Shanxi Province, Zhang and Zhao (2005) recognised a subgroup of visitors who had a significantly stronger interest in visiting natural areas than the remainder. Members of this group were typically well-educated professionals or white-collar workers with annual incomes over US\$2250 (Zhang and Zhao 2005). Other areas studied include Zhangjiajie (Quan 2004; Zhong, Deng and Xiang 2008), Wuyi Mountain (Wu and Hu 2004); the limestone mountains of southwestern China (Cai 2006); the Three Gorges area (Yuan 2006); Lougouantoi National Forest Park (Yu and Sun 2006), and Gudoughan Nature Reserve in Guangdong Province (Xu, Qiu and Xie 2007).

Whilst the stated motivations of domestic visitors to Chinese protected areas are thus quite similar to those nominated by Western domestic visitors to Western protected areas (Eagles and McCool 2003; Weaver 2005; Weaver and Lawton 2007), there are some significant differences in travel patterns and on-site activities. A survey conducted by Huang et al (2003) in Jiangsu Province, for example, found that Chinese domestic tourists engaged in shengtai lüyou differ from their North American ecotourism counterparts (Wight 1996a, b) in three critical regards. Their average length of stay is less than half as long, $<3$ days cf. $>7$ days; they are more likely to travel in organised package tours; and they learn about their destinations principally from newspapers and television, rather than their own investigations.

Information useful in characterising shengtai lüyou is available for outbound Chinese tourists to three Western nations, namely Canada, Australia and South Africa. Until the mid 1990s, international outbound tourism from China was quite heavily restricted and officially ignored (Arlt 2006). By 2005, however, there were over 31 million Chinese outbound tourists, though this includes shorthaul visits to Hong Kong, Macao and Taiwan.

A survey of over 1000 long-haul Chinese tourists carried out by two Australian tourism promotion organisations (DAMA \& TQ 2005) found that over one quarter had included nature-based tours in their last trip, and that the majority of these tourists listed "seeing wildlife in natural surroundings" (79\%), "visiting ecological sites" (68\%) and "walking in untouched natural environments" (60\%) as key goals. These 
longhaul international tourists were relatively wealthy, with annual incomes 8-24 times mean per capita GDP (DAMA \& TQ 2005), so they are socioeconomically distinct from domestic tourists visiting forest parks. Chinese visitors to Australia surveyed by $\mathrm{Yu}$ and Weiler (2001) said they were interested in beaches, parks, historic sites and Aboriginal culture. Surveys of visitors to Australia's Great Barrier Reef by Pearce (2004) found that Chinese visitors were more active and more interested in learning than visitors from other Asian nations. Chinese tourists surveyed by the Canadian Tourism Commission (2001) perceived Canada as a clean, safe country with outstanding natural scenery, and were keen to experience a different culture, visit historical sites, and watch wildlife. None of these surveys, therefore, provide sufficient detail to test whether Chinese outbound tourists bring Chinese concepts of shengtai lüyou with them when they travel overseas.

The majority of international inbound visitors to China are overseas Chinese residents, followed by Japanese and other Asian tourists (Zhu and Ye 2005). There are far fewer visitors from the West. A 2003 survey found that three quarters of Japanese visitors considered natural landscapes as an important factor in choosing China as a holiday destination (Hou 2005). A survey of 687 domestic and international visitors to Yunnan Province by Ye and Xue (2005) found that Western international ecotourists visiting China had higher environmental awareness and greater respect for traditional culture than their Chinese domestic counterparts, and greater preferences for independent individual travel and activities. These surveys, however, did not make any direct comparison between Western and Chinese domestic, or Western and Chinese international travelers, so any cultural differences are confounded with socioeconomic patterns.

\section{DISCUSSION}

\section{Similarities and distinctions}

The Chinese concept of shengtai lüyou, both in principle and in practice, contains a great deal in common with the Western concept of ecotourism; and indeed, the term shengtai lüyou first appeared in the Chinese-language academic literature as a direct translation of the term ecotourism in the English-language academic literature. In 
addition, there are many similarities in the practical contexts in which the two terms have been used: for example, as regards recreational use of public protected areas and forest lands. As in the West, there is also a contrast between environmentally and commercially oriented views of shengtai lüyou. The former focuses on minimizing tourist impact through management and education, and contributing to conservation of local communities. The latter focuses on revenue generation and regional economics, and includes a broad range of adventure-based activities as well as those based on nature appreciation and local cultures.

There are, however, some significant distinctions between shengtai lüyou and ecotourism, both as discussed in the Chinese-language academic and government literature, and as implemented in practice. These are differences of degree rather than absolute distinctions, but they are significant nonetheless. The key distinctions relate to: size and scale; the importance of human health outcomes; and the interdigitation of nature and culture, both architectural and literary. There is also a historical difference of context in university teaching, outlined earlier.

The majority of Western discourse on ecotourism has considered it, either explicitly or implicitly, as a relatively small-scale activity (Weaver 2001; Buckley 2003; Weaver and Lawton 2007). The environmental management of tourism at larger scales has been addressed under the rubric of sustainable or responsible tourism rather than ecotourism (Buckley 2008). Similarly, the larger-scale product sector of which ecotourism forms a part has been addressed under the headings of nature-based tourism (Newsome, Moore and Dowling 2002; Buckley, Pickering and Weaver 2003), or adventure tourism (Swarbrooke, Beard, Leckie and Pomfret 2003; Buckley 2006). The mechanisms by which ecotourism principles could be mainstreamed into mass tourism have also been considered to some degree (Buckley 2007). Ecotourism itself, however, has been treated as a small-scale, small-group activity, and this feature is frequently advertised in the marketing materials of commercial ecotourism companies. This restriction, either in scale or in group size, does not seem to have been transferred into the Chinese concept of shengtai lüyou. One Chinese commentary on Western ecotourism (Chen and Peng 2001) did indeed refer to this issue, but it does not seem to have been taken up generally. Many of China's protected areas, for example, receive many million visitors every year, a scale reached 
by only a few of their Western counterparts. The few published data available also indicate that Chinese domestic tourists engaged in shengtai lüyou prefer to travel in significantly larger groups than their Western counterparts (Huang et al 2003).

The value of nature-based tourism and recreation to individual physical and mental wellbeing seems to have received significantly more attention for shengtai lüyou than ecotourism. In the West, a few parks agencies have promoted the potential health benefits from visiting parks, and a very small number of medical insurance corporations have begun to consider the benefits of organised outdoor recreation programmes. These initiatives, however, have not been carried out under the name of ecotourism; and neither academic, government nor industry literature on ecotourism considers health components. In China, in contrast, several analyses of shengtai lüyou definitions specifically include health considerations (Guo 1997; Wu and Wu 2001; Shi and Yu 2002; Wu 2003). In addition, research on the health benefits essentially of fresh air (Zhong, Wu and Xiao 1998; Shi, Shu and Zhong 2004) has been carried out with specific reference to shengtai lüyou. It appears, therefore, that this criterion does indeed differentiate between ecotourism and shengtai lüyou. This difference may well reflect a broader cultural divergence between China and the West. Even in China's greatest cities, it is commonplace for residents of all ages to practice tai chi or other exercises in urban parks or the roofs of buildings, whereas their Western counterparts are more likely to patronise indoor gymnasia.

The third key distinction reflects the different perceptions of the relationship between humans and nature. In China, the traditional cultural perception, essentially an aesthetic one, is that nature can be improved by human artistic and architectural artefacts. As a result, it is commonplace that the icon scenic sites which form the attractions for shengtai lüyou will not only have historical connotations in art and literature, but also modern structures and sculptures which are intended to enhance the view. Interestingly, to Western eyes many of these structures have the opposite effect.

In Western history, there have indeed been periods when particular social groups in particular countries also held the view that human intervention would improve the aesthetics of natural landscapes. Many large estates owned by wealthy individuals in Europe, for example, were historically laid out with this idea in mind; and this attitude 
was also part of the pioneer culture in the American West and in early European settlement of Australia. During the period when ecotourism concepts have evolved, however, there has been a strong and dominant cultural perception in the West that for recreation as well as conservation, nature in protected areas is at its best when unsullied by human impact. Even though many protected areas are heavily managed, the goal of management regimes is generally to maintain the protected ecosystems in a pristine and primeval state, contrasting strongly with the heavily modified human rural landscapes used for primary production.

This distinction between China and the West is principally one of cultural perception rather than one of management practice. As in the West, modern China has protected areas distinguished from production landscapes, and extensive environmental pollution caused by industrialised primary production (Wang, Webster, Finlayson and Barnett 2008). As in China, the West has extensive infrastructure within many protected areas; and indeed, continuing pressure from the commercial tourism industry to build yet more. In addition, some of the world's most highly regarded Western ecotourism enterprises are ecolodges in private wildlife reserves where luxury low-impact accommodation is closely integrated with both visitor activities and conservation goals (Buckley 2003).

The distinction is thus at a more idealised level. Irrespective of the degree of effort, comfort or luxury which an individual Western ecotourist expects, the spectacle they are paying to see is one of wild nature, behaving as if humans were not present. The issue of feeding wildlife to attract them for tourists, for example, is contentious for precisely this reason, that it modifies the functioning of the ecosystem and species concerned. In shengtai lüyou, in contrast, the icon sites and idealised spectacles have cultural connotations, whether poetic or religious, and human modifications to the natural environment to reflect or display these are considered as a critical component of the site's aesthetic attraction. Once again, this difference reflects a key cultural divergence between China and the West, and this is explored further below.

\section{Cultural Context and Antecedents}


Just as the concept of ecotourism in the West arose from a long history of outdoor recreation and nature conservation, the concept of shengtai lüyou evolved within a context of Chinese cultural history. There are four particular aspects which appear to have had a key influence.

The first is literature. Whilst China has indeed had many different ruling dynasties and has included different ethnic groups at different times, it has maintained a coherent written literature, derived from a large geographic area, for much longer than the West. The West does indeed have written Greek and Latin literature from over 2000 years ago, including poetry as well as history, and later traditions such as the nature poetry of Wordsworth in the UK. Relatively few people in the modern West, however, especially the Anglophone nations, are familiar with their own historical cultural heritage of art and literature. Of course, this may also be true for modern China. Traditional painting and poetry, however, are still taught routinely in Chinese schools, whereas in Western schools these are considered specialist subjects.

The second aspect is the relationship between humans and nature in religion and philosophy. Two particular ancient Chinese philosophies, namely Taoism and Confucianism, still form pervasive underpinnings to many modern Chinese attitudes (Dallmayr 1993; Li 2006). In particular, these philosophies view humans as part of nature, an idea expressed by "a sentiment of consanguinity between persons and nature" (Shaner 1989; Liang and Zhang 2003). In the West, this is a minority perspective, associated either with the scientific disciplines of biology, ecology and related fields, or with the moral philosophies of conservation organisations. The more powerful majority perspective, which drives most governments and private corporations, is apparently based on a utilitarian interpretation of the Christian Bible, namely that humans have "dominion" over nature. The alternative Biblical interpretation that, as "stewards" of nature, humans have a responsibility to protect it, receives little practical expression. Equally, however, the Confucian ideal of harmony between nature and humanity may not be well reflected in modern Chinese society. Pursuit of individual material wealth through competition with other people, with limited concern for impacts upon the natural environment, seems to be as commonplace in China as in the West (Fishman 2006). However modern Chinese 
society may function more generally, however, the practice of interlinking cultural and natural attractions has a very strongly-established philosophical background.

The third key aspect, closely related to that examined above, is the question whether humans can and should improve upon nature, with particular reference to protected areas. There is indeed a difference of opinion between China and the West, but it is a fine, subtle and psychological distinction related to attitude, easily masked by the broad similarities in terms of practice. Both China and the West modify natural environments very heavily and extensively to serve human economic and material wellbeing, with rather small areas set aside for conservation. In both China and the West, these conservation areas are also used for recreation, and parks management agencies build visitor infrastructure intended to enhance the opportunities for visitors to enjoy nature. The key distinction is that in the West, the aim or ideal for a protected area is pristine nature unsullied by human impact, and the goal of visitor infrastructure is generally to provide views of nature without any visible human artefacts. In China, in contrast, the aesthetic ideal may include human artefacts, art or calligraphy which has been deliberately built, carved or painted as part of the icon view for visitors.

The distinction is an ideal one, because there are considerable complexities in practice. Many views in Western protected areas do indeed contain human artefacts, though they are more likely to be roads and powerlines than sculptures or paintings. Artwork on rocks or caves may still be appreciated as cultural heritage in the West, but only if it is ancient. Words written in modern paint would be considered merely graffiti, detracting from the value of the view and environment. This distinction was well illustrated in Australia some years ago when individuals claiming to be modern representatives of the traditional Aboriginal owners of a particular rock art site, painted over the traditional ochre drawings using modern acrylic paints. This caused widespread outrage. Those responsible argued that it was a traditional duty of rock art custodians to refresh the images by repainting them, and the fact that they had used modern acrylic paints rather than traditional ochre was irrelevant. For many, however, the materials as well as the image were critical to the heritage value of the artwork.

There are also some significant differences in the way that human interventions in Chinese protected areas are viewed by Chinese and Western visitors respectively. To 
Western eyes, Chinese visitor infrastructure is often very intrusive into natural landscapes, and has an industrial resonance due to intensive use of concrete and indeed modern paints. To Western sensibilities, these clash strongly with the natural landscapes. To Chinese visitors, in contrast, the close interweaving of nature and human artefacts yields a feeling of consonance rather than dissonance (Lin 2000).

The fourth and final key component of the Chinese cultural context for shengtai lüyou is a long concern for nature in both poetry and religious practice. The earliest historical document in China, known as the Shangshu, records that Xun, the emperor of China about 4100 years ago, had a religious obligation to climb particular mountains, such as those of Tai and Heng, once every five years (Zhong et al 2003). Around Longhu Mountain in Jiangxi province, an extensive series of Taoist temples and monasteries were constructed long ago on peaks and cliff tops, and have been immortalised in Chinese art and literature for many centuries. Tai Mountain in Shandong province has remained a symbolic and iconic site for millennia. A famous verse written by the poet $\mathrm{Du} F u$, who lived from 712-770 AD, said of Mt Tai “one day I shall climb clear to the summit, see how small the surrounding mountaintops appear as they lie below me” (Franklin 2003; Hsieh 1994). During the Ming dynasty from 1368-1644 AD, the emperor Zhu Li prohibited deforestation around temples, which has lead to successful protection of old growth forest at religious sites until the present (Zheng 2000). Rivers and lakes have also attracted attention: Sofield and Li (1998: 367), for example suggest that "when Western tourists look at the Yangtze, they see a river; the Chinese see a poem replete with philosophical ideals”.

\section{CONCLUSIONS}

We may draw two principal conclusions: first, that whilst shengtai lüyou and ecotourism are similar in many ways both in principle and practice, there are some key differences as regards health, aesthetics and scale; and second, that these differences have arisen because of the different cultural context and historical antecedents within China and the West.

For the vast majority of Chinese stakeholders involved in the discussion and development of shengtai lüyou, both the day-to-day setting and the information 
available have been entirely Chinese: it is only a small number of researchers who have been exposed simultaneously to English-language materials. These researchers provide a relatively thin or narrow link, on this particular topic, between two enormous and dynamic bodies of thought and action in China and the West respectively. In the West, the growth of outdoor tourism, protected area visitation, and concern over the environmental impacts of the tourism industry led to the concept of ecotourism. In China, there have been parallel trends in outdoor tourism, protected area visitation and concern over the environmental impacts of tourism, but within a somewhat different country and civilisation. The Western concept of ecotourism, therefore, has not been adopted wholesale within China: rather, it acted as a seed crystal, a timely concept which allowed the parallel concept of shengtai lüyou to arise from parallel issues and practices with regards to tourism and environment in China. Debates over the precise definition and criteria for shengtai lüyou, and over the appropriate ways to put it into practice, have occurred within the Chinese language and between Chinese stakeholders in the same way that parallel debates occurred in the West. As a result, there is now a self-sustaining concept of shengtai lüyou within China, which is used and understood by Chinese stakeholders whether or not they have had any direct exposure to the Western concept of ecotourism.

If the link from the western literature of ecotourism into Chinese thought has been thin, the reciprocal link from shengtai lüyou into Western thought has been even thinner. A small number of English-language authors, as outlined earlier, have commented on various aspects of tourism and environment in China, with particular relevance to protected area management and to tourist motivations, but generally restricted to single sites. Even fewer, notably Sofield and Li (1998), have commented specifically on the differences in cultural context, but without drawing any distinction between ecotourism and shengtai lüyou. Just as the West has drawn at times upon the millennia of Chinese art, literature and history, however, perhaps the Western discourse on ecotourism can now also gain from an understanding of shengtai lüyou, and arguably also from its analogues in other countries, languages and cultures. 
Ralf Buckley and Carl Cater are members of the International Centre for Ecotourism Research at Griffith University, Gold Coast, Qld, Australia 9726. E-mail <r.buckley@griffith.edu.au> . Zhong Linsheng and Tian Chen are Research Professors at the Academy of Science Institute for Geographical Sciences and Natural Resources in China.

Acknowledgement This research was carried out whilst Zhong Linsheng was a Visiting Fellow at the International Centre for Ecotourism Research, funded by the Academy of Science Institute for Geographical Sciences and Natural Resources in China. 


\section{REFERENCES}

Arlt, W.

2006 China’s Outbound Tourism. London and New York: Routledge.

Braden, K., and N. Prudnikova

2008 The Challenge of Ecotourism Development in the Altay Region of Russia. Tourism Geographies 10:1-21.

Buckley, R.

2000 NEAT Trends: Current Issues in Nature, Eco and Adventure Tourism. International Journal of Tourism Research 2:437-444.

2003 Case Studies in Ecotourism. Oxford: CAB International.

2004 Ecotourism Land Tenure and Enterprise Ownership: Australian Case Study. Journal of Ecotourism 3:208-213.

2006 Adventure Tourism. Oxford: CAB International.

2007 Is Mass Tourism Serious about Sustainability?. Tourism Recreation Research 32:70-72.

2008 Testing Take-Up of Academic Concepts in an Influential Commercial Tourism Publication. Tourism Management 29:721-729.

Buckley, R., C. Pickering and D. Weaver, eds.

2003 Nature-Based Tourism, Environment and Land Management. Oxford: CAB International.

Cai, Y-L.

2006 Eco-tourism: an Approach to Escaping from the 'Poverty Trap' in the Karst Mountains of Southwestern China. China Population Resources and Environment 16:113-116. (in Chinese).

Canadian Tourism Commission s(CTC)

2001 Research on the Chinese Outbound Travel Market Report. Ottawa: CTC.

Cater, E. 
2006 Ecotourism as a Western Construct. Journal of Ecotourism 5:23-39.

Chen, Z-Z.

1996 Ecotourism Resources in Xilinguole Grassland. Journal of Arid Land Resources and Environment 10:58-66. (in Chinese).

Chen, H., and C-C. Liu

1998 Ecotourism: an Evaluation of its Approaches. Journal of Northwest University (Philosophy and Social Sciences Edition) 28:24-26. (in Chinese).

Chen, Z-X., and J. Peng

2001 The Essentials of Ecotourism. Journal of Guilin Institute of Tourism 12(64):5457. (in Chinese).

Chen, Z-X., Y-L. Wang and Z-W. Liu

2001 Progress in Ecotourism Research. Advances in Earth Sciences 16:556-562. (in Chinese).

Cheng, Z-H. and J-T. Zhang

2001 Organisation and Research Development of Ecotourism. Economic Geography 21:110-113. (in Chinese).

China National Tourism Administration (CNTA)

2007 Major Statistics of China Tourism

2006

<http://www.cnta.com/news_detail/newsshow.asp?id=A20071023110273962782>

(15 October 2007).

China State Forest Administration (CSFA)

2006 Construction and development of Forest Park in China during 2001-2005 <http://www.gov.cn/gzdt/2006-04/30/content_271753.htm> (13 July 2006).

Dai, G-Q. and Y.-Y. Shu 
2000 Analysis of Net Asset/Earning Ratios for Listed Tourism Companies. Journal of Shanghai University (Social Sciences Edition) 2:76-80. (in Chinese).

Dallmayr, F

1993 Tradition, Modernity and Confucianism. Human Studies 16:203-211.

Destination Australia Market Alliance and Tourism Queensland (DAMA and TQ) 2005 The Chinese Ecotourism Market

<http://www.tq.com.au/fms/tq_corporate/research/fact_sheets/the_chinese_ecotouris m_market.pdf $>$ (13 July 2006).

Deng, B. and B.-H. Wu

2006 International Progress in Research on Community-based Ecotourism. Tourism Tribune 21:84-88. (in Chinese).

Eagles, P. and S. McCool

2003 Tourism in National Parks and Protected Areas: Planning and Management Oxford: CAB International.

Fennell, D.

1999 Ecotourism. London: Routledge.

Fishman, T.

2006 China Inc.: The Relentless Rise of the Next Great Superpower. New York: Pocket Books.

Franklin, A.

2003 Tourism: An Introduction. London: Sage.

Guo, L-X.

1997 Ecotourism in China: the Foundation of Sustainable Tourism. Progress in Geography 16:1-10. (in Chinese).

Han, N-Y. and R. Zhuge 
2001 Ecotourism in China’s Nature Reserves: Opportunities and Challenges. Journal of Sustainable Tourism 9:228-242.

Hou, Y.

2005 Outbound Tourism Trends in Japan. Journal of Beijing International Studies University 5:97-102. (in Chinese).

Hsieh, D.

1994 Du Fu’s “Gazing at the Mountain”. Chinese Literature: Essays, Articles, Reviews (CLEAR) 16:1-18.

Huang, Z-F., Z. Chen and X. Zhang

2003 Comparative Research on Behavior Characteristic of Ecotourists at Home and Abroad. Modern Economic Research 12:71-73. (in Chinese).

Huang, Y., J.-Y. Deng, J. Li and Y. Zhong

2008 Visitors' Attitudes towards China’s National Forest Park Policy, Role and Functions, and Appropriate Use. Journal of Sustainable Tourism 16:63-84.

\section{IUCN}

1994 Guidelines for Protected Areas Management Categories. Cambridge, UK and Gland, Switzerland: IUCN.

Jin, B., R.-Y. Wang and Y.-L. Cai

2001 Origin of Ecotourism, and Applications in China. Chinese Journal of Ecology 20:56-59. (in Chinese).

Kong, F-B. and J. Wang

2006 Research and Prospects for Ecotourism Planning in Nature Reserves. World Forestry Research 19(5):77-78. (in Chinese).

Kuang, $\mathrm{H}$.

2004 Wulingyuan: “Yellow Card” Warning. Green China, October (in Chinese). 
Li, J.

2002 Development and Challenges to the Protected Areas of Mainland China. Paper presented at the Proceedings of IUCN World Commission on Protected Areas (WCPA) 4th Conference on Protected Areas of East Asia.

Li, W-J.

2006 Community Decision Making: Participation in Development. Annals of Tourism Research 33:132-143.

Li, X.

2006 The Confucian Theory for Man and Nature. Journal of Beijing Normal University (Social Sciences) 4:131-135. (in Chinese).

Li, H-B. and J-H. Chen

2006 Evaluating the Classification of Ecotourism. Human Geography 21(6):62-66. (in Chinese).

Li, W-J. and N-Y. Han

2000 Ecotourism Management in China’s Nature Reserves. Ambio 30:62-63.

Liang, S-M. and S-Y. Zhang

2003 Ecotourism and the Ecology of the Travel Culture. Ecological Science 22:183185. (in Chinese).

Li, S-Y., L. Gao, Q-H. Wei and B. Yu

2005 Study on the Essence of Ecotourism. Journal of Beijing Forestry University (Social Sciences) 4:24-30. (in Chinese).

Lin, J-Y.

2000 On the Concept of the Harmony between Nature and Human in Traditional China. Studies In Dialectics of Nature 9:4-8. (in Chinese).

Lindberg, K., C. Tisdell and D. Xue 
2003 Ecotourism in China’s Nature Reserves. In Tourism in China, A. Lew, L. Yu, J. Ap and G. Zhang, eds., pp. 103-125. New York: Haworth Press.

Liu, J-M.

1998 Advances and Research Planning in Ecotourism. Chinese Journal of Applied Ecology 9:327-331. (in Chinese).

Liu, X. and J. Bao

1996 Development of Research on Environmental Impacts of Tourist Development. Geographical Research 15:92-99. (in Chinese).

Liu, J. and R. Dowling

1991 Integrating Tourism Development and Environmental Conservation in China. In Ecotourism: Incorporating the Global Classroom, R. Weiler, ed.,. Canberra: Bureau of Tourism Research.

Liu, J-S., Q. Kong and J. Chen

1997 A Study of the Ecotourism Development in Nature Preserved Regions in China. Human Geography 12(4):20-24. (in Chinese).

Liu, J-L., S-Q. Chen and Z-Y. Tang

2006 Discussion on Ecotourism Standardization in China. Scientia Silvae Sinicae 42(4):101-105. (in Chinese).

Lu, Y.T. and J.J. Wang

2004 Ecotourism (second ed.). Beijing: Tourism Education Press. (in Chinese).

Mader, R.

2003 Latin American Ecotourism: What Is It? In Global Ecotourism Policies and Case Studies: Perspectives and Constraints, M. Lück and T. Kirstges, eds., pp. 100-107. Clevedon: Channel View.

Newsome, D., S. Moore and R. Dowling 
2002 Natural Area Tourism: Ecology, Impacts, and Management. Clevedon: Channel View.

Niu, Y-F.

1999 Sustainable Tourism, Ecotourism and Implementation. Geographical Research 18:179-184. (in Chinese).

Pearce, $\mathrm{P}$.

2004 Assessing Market Convergence and Divergence: Studies of Visitors to Australia’s Great Barrier Reef. Glasgow: Tourism - State of the Art II.

Quan, H.

2004 Review of Research on Ecotourism Zone Construction. Areal Research and Development 23(93):70-73. (in Chinese).

Shaner, D.

1989 The Japanese Experience of Nature. In Nature in Asian Traditions of Thought: Essays in Environmental Philosophy, J. B. Callicott and R. T. Ames, eds., pp. 163181. New York: State University of New York Press.

Shen, X.

1995 Developing Forest Tourism and Forests. China Forestry Business 1:14-16. (in Chinese).

Shi, Q. and S. Yu

2002 The Health Function of Ecotourism Resorts, and its Application in Construction of Eco-Health Parks. Journal of Zhejiang Forestry College 19:69-73. (in Chinese).

Shi, Q., H-F. Shu and L-S. Zhong

2004 Research on Evaluation of Aeroanions in Forest Recreation Areas. Scientia Silvae Sinicae 40:36-40. (in Chinese).

Sofield, T. and F-M. Li 
1998 Tourism Development and Cultural Policies in China. Annals of Tourism Research 25:362-392.

2003 Processes in Formulating an Ecotourism Policy for Nature Reserves in Yunnan Province, China. In Ecotourism Policy and Planning, D. A. Fennell and R. K. Dowling, eds., pp. 141-167. Oxford: CAB International.

Stone, M. and G. Wall

2003 Ecotourism and Community Development: Case Studies from Hainan, China. Environmental Management 33:12-24.

Swarbrooke, J., C. Beard, S. Leckie and G. Pomfret

2003 Adventure Tourism: The New Frontier. Oxford: Butterworth-Heinemann.

Tan, H-Y., K-P. Gu and W-H. Chen

2007 Problems and Recommendations for Ecotourism Development in China, Based on its Public Welfare Characteristics. Forest Resources Management 5:19-22. (in Chinese).

The International Ecotourism Society (TIES)

1990 What is ecotourism? < http://www.ecotourism.org > (06 Feb 2008).

Wang, X-P.

1993 Significance and Methods for Developing Ecotourism in Protected Areas. Journal of Plant Resources and Environment 2:49-54. (in Chinese).

1995 Progress on Ecotourism and Protected Areas. China Biosphere 2:17-22. (in Chinese).

Wang, E-K.

1998a Ecotourism and Environmental Protection. Tourism Tribune 2:14-16. (in Chinese).

Wang, S-L.

1998b The History of Tourism in China. Beijing: Tourism Education Press. (in Chinese). 
Wang, Y., X-D. Gou and X-H. Zhang

2001 Discussions on the Conceptual Generalization of Ecotourism. Journal of Northwest Forestry University 16:54-58. (in Chinese).

Wang, M., M. Webster, B. Finlayson and J. Barnett

2008 Rural Industries and Water Pollution in China. Journal of Environmental Management 86:648-659.

Weaver, D.

2001 The Encyclopedia of Ecotourism. Oxford: CAB International.

2005 Comprehensive and Minimalist Dimensions of Ecotourism. Annals of Tourism Research 32:439-455.

Weaver, D. and L. Lawton

2007 Twenty Years On: The State of Contemporary Ecotourism Research. Tourism Management 28:1168-1179.

Wen, J. and C. Tisdell

2001 Tourism and China’s Development: Policies, Regional Economic Growth and Ecotourism. Singapore: World Scientific.

Wight, P.

1996a North American Ecotourists: Market Profile and Trip Characteristics. Journal of Travel Research 34:2-11.

1996b North American Ecotourism Market: Motivations, Preferences, and Destinations. Journal of Travel Research 35:3-10.

Wu, Z-W.

2003 Further Exploitation of Healthcare Tourism Resources in Forestry Recreation Areas. Journal of Beijing Forestry University 25:63-67. (in Chinese).

Wu, Z-W. and L-Y. Hu 
2004 Study on the Psychological Needs and Behavioral Characteristics of Ecological Tourists, with a Case Study of the Wuyi Mountain National-level Nature Reserve. Journal of Central South Forestry University 24:42-48 (in Chinese).

Wu, C-C. and Z-W. Wu

2001 Research on the Background and Development Direction of Ecotourism. Journal of Central South Forestry University 21:37-41. (in Chinese).

Xiao, $\mathrm{H}$.

2000 China's Tourism Education into the $21^{\text {st }}$ Century. Annals of Tourism Research 27:1052-1055.

Xiao, J-Z. and G-M. Xiao

2005 A Discussion of Sustainable Development for Ecotourism in China. Journal of Zhaoqing University 26:35-38. (in Chinese).

$\mathrm{Xu}, \mathrm{H}-\mathrm{G}$.

2006 A Model Study in the Development of Ecotourism Destination. Tourism Tribune 21(8):75-80. (in Chinese).

$\mathrm{Xu}, \mathrm{G}$. and C. Kruse

2003 Ecotourism in China’s Nature Reserves. In Tourism in China, A. Lew, L. Yu, J. Ap and G-R. Zhang, eds.,. Binghamton: Haworth.

Xu, S-J., P-H. Qiu and G-Z. Xie

2007 Impacts of Ecotourism Development on Landscape Ecology, with Particular Reference to Gudoushan Nature Reserve, Guangdong Province. Acta Ecologica Sinica 27:4045-4056. (in Chinese).

Yang, G-H., L-S. Zhong and Q-Z Ming

2000 Ecotourism. Beijing: Higher Education Press. (in Chinese).

Yang, G-H., C-H. Wen and Y-H. Wang 
2002 Environmental effects of ecotourism in Bita Lake Natural Reserve, Yunnan Province of China. Journal of Mountain Science 20:752-756. (in Chinese).

Yang, B-S., Z-Y. Ouyang and P. He

2005 Review of Ecotourism Research Progress. Journal of Zhuzhou Institute of Technology 19:60-63. (in Chinese).

Ye, W. and X-M. Xue

2005 Research on the Localization of Ecotourism. China Population, Resources and Environment 15:55-61. (in Chinese).

Yuan, Y.

2006 Ecological Tourism in the Three Gorges Ethnic Areas. Journal of South-Central University for Nationalities (Humanities and Social Sciences) 26:48-51. (in Chinese).

Yu, L-X. and G-N. Sun

2006 Models of Deep Ecotourism Development in Louguantai National Forestry Park. Journal of Mountain Science 124:727-773. (in Chinese).

$\mathrm{Yu}, \mathrm{X}$. and B. Weiler

2001 Mainland Chinese Pleasure Travellers to Australia: Leisure Behavior Analysis. Tourism, Culture and Communication 3:81-91.

Yuan, J., D-T. Wu, X. Chang and Z-Z. Wu

2007 Some Doubts about Ecotourism. Commercial Business 10:189-191. (in Chinese).

Zhang, J-X

2002 A Basic Discussion on the Expanding Phenomenon of Ecotourism. Journal of Qinghai Normal University (Philosophy and Social Sciences) 4:89-92. (in Chinese).

Zhang, Y-X.

2007 Examining Improvements in Ecotourism Theory and Chinese Standards for Ecotourism Demonstration Areas. Ecological Economics 11:143-146. (in Chinese). 
Zhang, Q-J. and Y. Hai

2000 Review of Ecotourism Research in China. Journal of Xinjiang Normal University (Social Science) 21:104-107. (in Chinese).

Zhang, D-M. and Z-M. Li

2004 Qomolangma National Nature Reserve, Tibet. Biological Education 9:57-58. (in Chinese).

Zhang, H-X. and Z-B. Zhao

2005 A Survey of Ecotourism Market Structure Based on Behavior and Attitude: Case Study of Taibai Mountain National Forest Park. Tourism Tribune 20:34-38. (in Chinese).

Zhang, J., B. Xu and M-Z. Huang

2005 Issues and Countermeasures for Developing Ecotourism in Nature Reserves in China. China Forestry Business 1:19-22. (in Chinese).

Zhao, S-D.

1999 Biodiversity and Conservation in Changbai Mountain Biosphere Reserve: Introduction and Progress. Ambio 28:639-641.

Zheng, Y.

2000 Discussion on Some Issues of Tourism History in China. Journal of Social Science of Hunan Normal University 29:60-66. (in Chinese).

Zhong, L-S.

2006 Ecotourism Area Standard of China (draft). Beijing: Chinese Academy of Sciences. (in Chinese).

Zhong, L-S. and R. Buckley

2007 Tourism Ecocertification in China. Annals of Tourism Research 34:808-811.

Zhong, J. and G-H. Yang 
2005 A Survey of Chinese College Students’ Ecological Awareness - Case Study in Yunnan University. Tourism Tribune 20:53-57. (in Chinese).

Zhong, L-S., C-C. Wu and D-N. Xiao

1998 Aeroanion Researches in Evaluation of Forest Recreation Resources. Chinese Journal of Ecology 17:56-60. (in Chinese).

Zhong, L-S., S-D. Zhao and B-H. Xiang

2003 Principles and Methods of Ecotourism Planning. Beijing: Chemical Industry Press. (in Chinese).

Zhong, Y-D., J-Q. Yuan and F. Luo

2006 Ecotourism Management. Beijing: Chinese Forestry Press. (in Chinese).

Zhong, C-L., J-B. Liu and L-J. Tong

2007 Patterns in Wetland Ecotourism. Anhui Journal of Agricultural Sciences 35:7579-7581. (in Chinese).

Zhong, L-S., J-Y. Deng and B-H. Xiang

2008 Tourism Development and the Tourism Area Life Cycle: A Case Study of Zhangjiajie National Forest Park, China. Tourism Management (in press).

Zhu, M-X. and Y-P. Ye

2005 A Discussion of Issues Associated with Japanese Visitors to China. Guangxi Social Science 3:45-47. (in Chinese). 
Table 1. Characteristics and comparisons of shengtai lüyou and ecotourism

\begin{tabular}{|c|c|c|c|c|c|c|c|c|c|c|c|}
\hline \multirow[t]{2}{*}{ Characteristics } & \multicolumn{8}{|c|}{ Shengtai lüyou } & \multicolumn{3}{|c|}{ Ecotourism } \\
\hline & $\begin{array}{l}\text { Wang } \\
1995\end{array}$ & $\begin{array}{l}\text { Guo } \\
1997\end{array}$ & $\begin{array}{l}\text { Chen } \\
\& \\
\text { Liu } \\
1998\end{array}$ & $\begin{array}{l}\text { Niu } \\
1999\end{array}$ & $\begin{array}{l}\text { Chen } \\
\text { \& } \\
\text { Peng } \\
2001\end{array}$ & $\begin{array}{l}\text { Wu } \\
\& \\
W u \\
2001\end{array}$ & $\begin{array}{l}\mathrm{Li} \text { et } \\
\text { al } \\
2005\end{array}$ & $\begin{array}{l}\text { Zhang } \\
2007\end{array}$ & most & $\begin{array}{l}\text { some } \\
\text { only }\end{array}$ & distinctions \\
\hline \multicolumn{12}{|l|}{ Attractions $^{\mathrm{a}}$} \\
\hline \begin{tabular}{|l} 
nature, \\
including \\
wildlife
\end{tabular} & * & $*$ & $*$ & b & $*$ & * & * & * & $*$ & $*$ & \\
\hline $\begin{array}{l}\text { cultural } \\
\text { heritage }\end{array}$ & & $*$ & & & $*$ & & $*$ & * & & * & \\
\hline $\begin{array}{l}\text { aesthetics, } \\
\text { poetic } \\
\text { connotations }\end{array}$ & & & & & $*$ & & & & & & $*$ \\
\hline \multicolumn{12}{|l|}{ Restrictions $^{\mathrm{b}}$} \\
\hline small-scale & & & & & * & & & & & $*$ & $?$ \\
\hline guidance & $*$ & $*$ & & & & & & & $*$ & $*$ & \\
\hline ethics & & & & & $*$ & & & & & $*$ & \\
\hline $\begin{array}{l}\text { ecological } \\
\text { perspective }\end{array}$ & $*$ & $*$ & & & $*$ & & $*$ & & & & $*$ \\
\hline $\begin{array}{l}\text { understand } \\
\text { nature }\end{array}$ & & & & & & $*$ & & & & $*$ & \\
\hline minimal-impact & $*$ & & & C & & & $*$ & * & $*$ & $*$ & \\
\hline \multicolumn{12}{|l|}{ Outcomes $^{c}$} \\
\hline $\begin{array}{l}\text { appreciate } \\
\text { nature }\end{array}$ & & $*$ & & & $*$ & $*$ & $*$ & & $*$ & $*$ & \\
\hline $\begin{array}{l}\text { understand } \\
\text { ecology }\end{array}$ & $*$ & & & & $*$ & $*$ & $*$ & & & $*$ & \\
\hline conserve nature & * & * & $*$ & c & & $*$ & * & $*$ & & $*$ & \\
\hline cherish culture & & $*$ & & & & & & * & & $*$ & \\
\hline $\begin{array}{l}\text { community } \\
\text { wellbeing }\end{array}$ & & & $*$ & $\mathrm{a}$ & * & & $*$ & $*$ & & $*$ & \\
\hline individual & & * & & & & $*$ & & & & & $*$ \\
\hline
\end{tabular}




\begin{tabular}{|c|c|c|c|c|c|c|c|c|c|c|c|}
\hline \multirow[t]{2}{*}{ Characteristics } & \multicolumn{8}{|c|}{ Shengtai lüyou } & \multicolumn{3}{|c|}{ Ecotourism } \\
\hline & $\begin{array}{l}\text { Wang } \\
1995\end{array}$ & $\begin{array}{l}\text { Guo } \\
1997\end{array}$ & $\begin{array}{l}\text { Chen } \\
\& \\
\text { Liu } \\
1998\end{array}$ & \begin{tabular}{|l|}
$\mathrm{Niu}$ \\
1999
\end{tabular} & $\begin{array}{l}\text { Chen } \\
\text { \& } \\
\text { Peng } \\
2001\end{array}$ & \begin{tabular}{|l} 
Wu \\
$\&$ \\
$W u$ \\
2001
\end{tabular} & $\begin{array}{l}\mathrm{Li} \text { et } \\
\text { al } \\
2005\end{array}$ & $\begin{array}{l}\text { Zhang } \\
2007\end{array}$ & most & $\begin{array}{l}\text { some } \\
\text { only }\end{array}$ & distinctions \\
\hline health & & & & & & & & & & & \\
\hline
\end{tabular}

a, b, c, author recognised 3 separate themes.

a i.e., ecotourism products are based on enjoyment of ...; i.e., it's only ecotourism if it includes or involves ... ${ }^{\mathrm{c}}$ i.e., the aims of ecotourism are to ... 
Table 2. Modern chronology of shengtai lüyou

\begin{tabular}{|c|c|}
\hline Year & Event \\
\hline 1993 & $\begin{array}{l}\text { Session on shengtai lüyou in parks, } 1^{\text {st }} \text { East Asia National Parks Conference, } \\
\text { Beijing }\end{array}$ \\
\hline 1993 & $\begin{array}{l}\text { Forest tourism branch established within Chinese Forestry Society to discuss } \\
\text { forest parks and shengtai lüyou in forests }\end{array}$ \\
\hline 1994 & Shengtai lüyou branch established in China Tourism Association \\
\hline 1994 & First Shengtai Lüyou Development Forum in China in Yunnan, in December \\
\hline 1996 & International ecotourism seminar in Wuhan in June, funded by UNDP \\
\hline 1996 & $\begin{array}{l}\text { China Agenda } 21 \text { adopted in October, with } 2 \text { shengtai lüyou demonstration } \\
\text { projects }\end{array}$ \\
\hline 1997 & $\begin{array}{l}\text { Sustainable tourism forum in Beijing in July, promoting shengtai lüyou as } \\
\text { highly significant in sustainable development }\end{array}$ \\
\hline 1999 & $\begin{array}{l}\text { Chinese tourism industry adopted a shengtai lüyou theme for the year, } \\
\text { promoting tour routes and the slogan 'Enjoying, Understanding and Conserving } \\
\text { Nature' }\end{array}$ \\
\hline 2001 & Shengtai Lüyou Committee established within Ecological Society of China \\
\hline 2002 & First Shengtai Lüyou Development Forum, Western China \\
\hline 2002 & $\begin{array}{l}\text { China Shengtai Lüyou Summit Forum, part of UN International Year of } \\
\text { Ecotourism }\end{array}$ \\
\hline 2003 & $\begin{array}{l}\text { Expert meeting on shengtai lüyou certification at China National Institute for } \\
\text { Standardisation in December }\end{array}$ \\
\hline 2004 & $\begin{array}{l}\text { International Conference on Khampa Shengtai Lüyou, Sichuan, in November, } \\
\text { sponsored by international NGOs }\end{array}$ \\
\hline 2004 & Second Shengtai Lüyou Development Forum, Hubei Province \\
\hline 2005 & $\begin{array}{l}\text { In June, China National Tourism Administration and State Environmental } \\
\text { Protection Agency published a Notice on "Further Reinforcement of Tourism } \\
\text { Environmental Protection", requiring accelerated development of standards for } \\
\text { shengtai lüyou }\end{array}$ \\
\hline 2005 & China International Forum on Shengtai Lüyou, Zhejang Province, November \\
\hline 2006 & $\begin{array}{l}\text { Seminar on Shengtai Lüyou Standard of China, Guangdong Province, } \\
\text { September }\end{array}$ \\
\hline 2006 & Third Shengtai Lüyou Development Forum, Jiangxi Province \\
\hline 2007 & $\begin{array}{l}\text { Fourth Shengtai Lüyou Development Forum and First Kunming International } \\
\text { Forum on Ecotourism, Yunnan Province }\end{array}$ \\
\hline
\end{tabular}

